\title{
Consecutive monitoring method for pecan orchards and discovery of a mysterious circle in a pecan orchard with UAV
}

\author{
H. Yamagata ${ }^{1} \cdot$ K. Noda ${ }^{2} \cdot$ J. J. Randall ${ }^{3} \cdot$ H. Kamiya ${ }^{1} \cdot$ K. Oki $^{1,4}$ \\ Received: 30 March 2021 / Accepted: 18 August 2021 / Published online: 1 November 2021 \\ (c) The Author(s) 2021
}

\begin{abstract}
In this study, we established consecutive monitoring methods using UAV in pecan orchards of 64 ha each, in San Simon, Arizona, USA. Activity monitoring, tree height map creation and ground surface temperature analysis of trees by UAV with near infrared (NIR)/TIR camera were conducted for pecan orchards in San Simon, Arizona, USA. Using established continuous monitoring methods, the UAV images of a 3-year-old pecan orchard showed circular traces of alfalfa cultivation prior to installation of pivot irrigation that was previously not observed. Tree growth measurements was compared to the trees planted inside and outside of the circle. Growth and tree health activity was found to be better when the trees were outside of the circle.
\end{abstract}

Keywords Remote sensing · Unmanned Aerial Vehicles (UAVs) · Thermal $\cdot$ NDVI $\cdot$ Pecan · 3D modeling

\section{Introduction}

Sustainable food production is a global issue due to concerns about food shortages because of an increasing human population [1]. To meet the growing food demand, many researches are utilizing remote sensing technologies to monitor the growth of agricultural crops and to reduce the amount of water and fertilizer used [2]. The use of remote sensing is useful to manage large-scale croplands. However, there are limitations such as lack of the spatial resolution or high operative cost in remote sensing technologies using satellite sensors and manned airborne platforms.

\section{K. Ok}

oki.kazuo@kuas.ac.jp

1 Institute of Industrial Science, The University of Tokyo, Tokyo, Japan

2 Faculty of Applied Biological Sciences, Gifu University, Gifu, Japan

3 Entomology, Plant Pathology, and Weed Science, New Mexico State University, Las Cruces, USA

4 Faculty of Engineering, Kyoto University of Advanced Science, Kyoto, Japan
In recent years, UAVs (Unmanned Aerial Vehicles) have attracted attention as a platform for remote sensing, and research that verifies their application to agriculture is also being conducted [3]. Using UAV, it is possible to take pictures with a spatial resolution of less than $1 \mathrm{~cm}$ depending upon the types of cameras. Data acquisition over a wide range of ground observation is possible by combining existing remote sensing technology with image acquisition using UAV. This approach is less expensive and more detailed than satellite and aircraft. The use of this technology for water management and for growth monitoring is expected to increase the production of agricultural crops and improve the yield prediction technology.

In this study, we established consecutive monitoring methods using UAV in pecan orchards of 64 ha each, in San Simon, Arizona, USA. The UAV had two cameras of near infrared $(0.7-1.0 \mu \mathrm{m}, 4 \mathrm{~cm}$ resolution) and thermal infrared (8-13 $\mu \mathrm{m}, 40 \mathrm{~cm}$ resolution) and observations were performed once every 2 weeks. We made whole maps of each orchard by creating a mosaic of the images of both cameras. Furthermore, changes could be monitored at a spot in the orchard by maintaining positional information to a map. We monitored the activity of pecan trees by NDVI and thermal images, and tree height by DSM (Digital Surface Model) which was made from a 3D model. Differences in growth of 
Fig. 1 UAV and installed devices

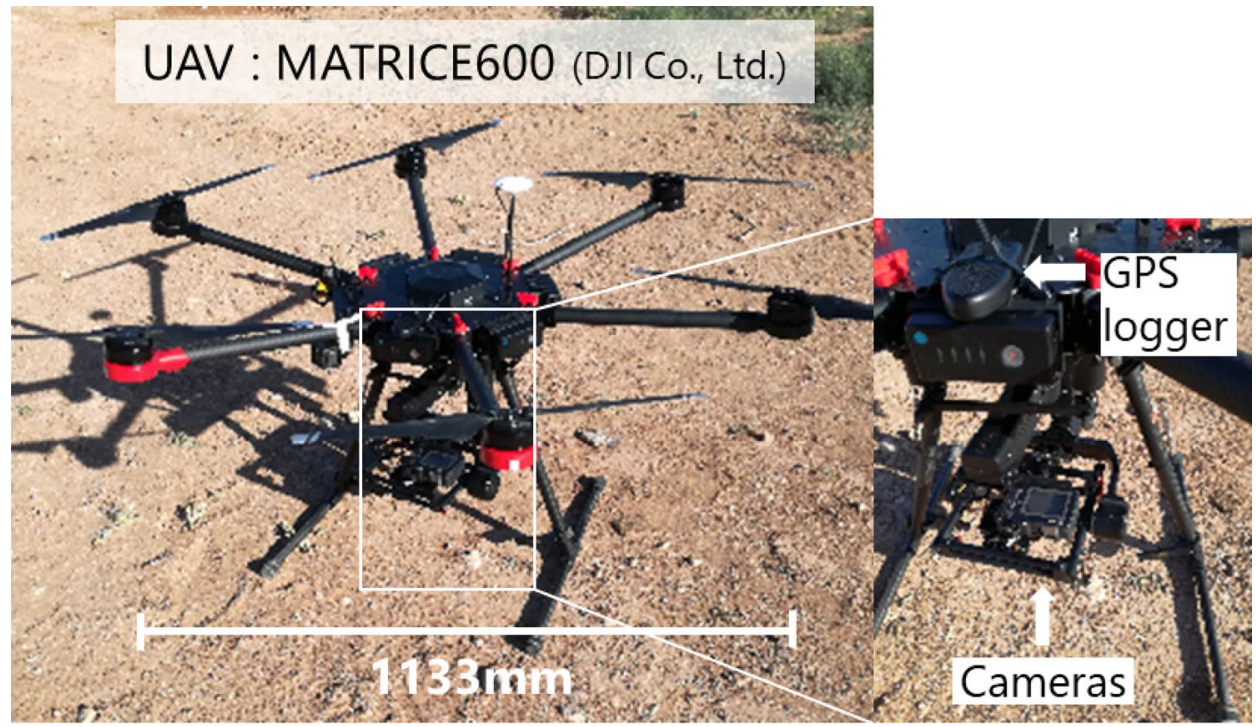

Table 1 Information of cameras and acquired data

\begin{tabular}{lll}
\hline & Visible near infrared & Thermal infrared \\
\hline Name of device & Yubaflex & Thermoshot \\
Spectral bands & R, G, NIR $(0.85 \mu \mathrm{m})$ & TIR $(8 \sim 13 \mu \mathrm{m})$ \\
Pixel number & 4000 pix $\times 3000$ pix & 160 pix $\times 120$ pix \\
Viewing angle & $\mathrm{H} 72.32^{\circ} \times \mathrm{V} 57.45^{\circ}$ & $\mathrm{H} 28^{\circ} \times \mathrm{V} 21^{\circ}$ \\
File format & RAW format & JPEG format with \\
& & temp informa- \\
& & tion \\
Spatial resolution & $4 \mathrm{~cm}$ & $40 \mathrm{~cm}$ \\
Data size & $12.5-14 \mathrm{MB} /$ image & $60-80 \mathrm{~KB} / \mathrm{image}$ \\
\hline
\end{tabular}

different varieties of pecan trees was observed by monitoring the activity of the trees by NDVI.

From established continuous monitoring methods, one observed UAV image showed that 3 years after planting the pecan trees, there were circular traces of alfalfa cultivation prior to the introduction of pivot irrigation that was not previously observed in the field.

\section{Materials and methods}

In this study, visible Near Infrared (NIR) images and Thermal Infrared (TIR) images were taken using UAV on a pecan tree orchard in San Simon, Arizona, USA. These images were then used to monitor plant activity and to create tree height maps.

\subsection{Image acquisition by UAV}

Observations were conducted by installing two digital cameras (visible Near-Infrared: Yubaflex, by BIZWORKS Co., Ltd., Thermal Infrared: thermoshot, by Nippon Avionics Co., Ltd.) in a hexa-copter type UAV (MATRICE 600, by DJI Co., Ltd.) as shown in Fig. 1. The UAV was automatically steered by software (InFlight, by Precision Hawk USA Inc.). The acquired image information from each camera is shown in Table 1. In this study, since the photographs were taken at a flying altitude of $120 \mathrm{~m}$, images were obtained with a spatial resolution of about $4 \mathrm{~cm}$ and about $40 \mathrm{~cm}$ in each of the NIR and the TIR. To acquire position information at the time of shooting, the UAV was equipped with a GPS logger (GPS Logger, by Aaronia AG.). The area of the target field was about 64 ha $(800 \times 800 \mathrm{~m})$, and the flight was carried out three times for one field due to the limitation of the UAV battery. The 650 images were observed in one field, and anti-aircraft signs were installed to enhance the matching accuracy between images.

In the orchard, pecan trees were planted at every 35 feet $(10.7 \mathrm{~m})$ in the east-west direction and 20 feet $(6.1 \mathrm{~m})$ in the north-south direction. As shown in Fig. 2, three varieties of pecan trees that included 'Western', 'Wichita' and 'Waco' were regularly planted. The orchard consisted of two rows from the eastern end were 'Western', the next five rows were 'Wichita', and the next two rows were 'Waco', and this order continued to the west end. The trees were third leaf in this field, but some trees were younger replants due to infections and dislodging caused by the wind. 


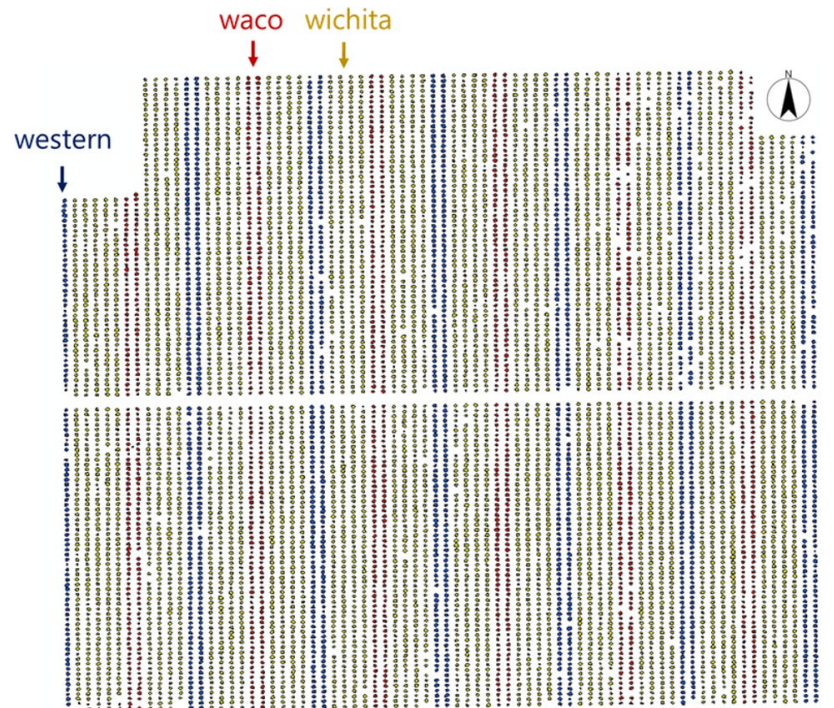

Fig. 2 Placement of Pecan varieties in the orchard

\subsection{Tree height map creation}

Tree height map creation and activity monitoring were performed from NIR images taken with UAV. The procedures are described below.

1. First, it was necessary to standardize the image taken with UAV using the value of the standard white board for each wavelength band. The NIR image consisted of an output of a luminance value expressed by 32 bits (floating point), as a false color image (NIR, visible red, green wavelength band corresponds to $\mathrm{R}, \mathrm{G}, \mathrm{B}$, respectively) using dedicated software. The solar radiation was normalized using a standard white board.

2. The standardized image was associated with the GPS logger's position and time information. Since neither the NIR nor TIR images have position information, the

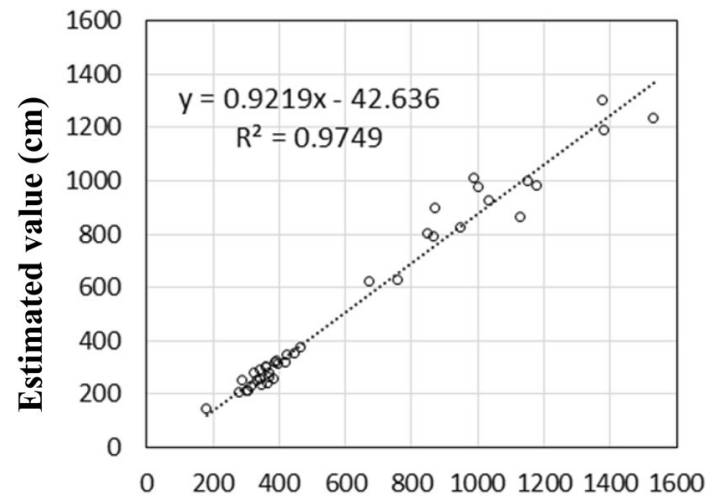

Measured value $(\mathrm{cm})$

Fig. 4 Linear regression of model estimation against actual measurement value of tree height

position information at the time of shooting was an output from the GPS logger mounted on UAV as a csv file (Fig. 3).

3. Analyzed with image processing software. Image processing software Photoscan (Agisoft LLC.) read the 650 images and position information files and created point clouds, meshes, 3D models, DSM (Digital Surface Model), and ortho mosaic images.

Tree height maps were created using the DSM as listed in step 3 in the above section. The DSM which is threedimensional data consisting of the elevation of the ground surface and including the height of buildings and trees, consisted of outputs with a resolution of about $16 \mathrm{~cm} /$ pixel as an altitude value. To eliminate irregular distortion occurring at every observation time, we removed distortion using the GIS software (ArcMap, ESRI), and the ground surface was corrected to be approximately $0 \mathrm{~m}$. To validate the height model and to correct errors, tree height measurements were

Fig. 3 GPS logger information

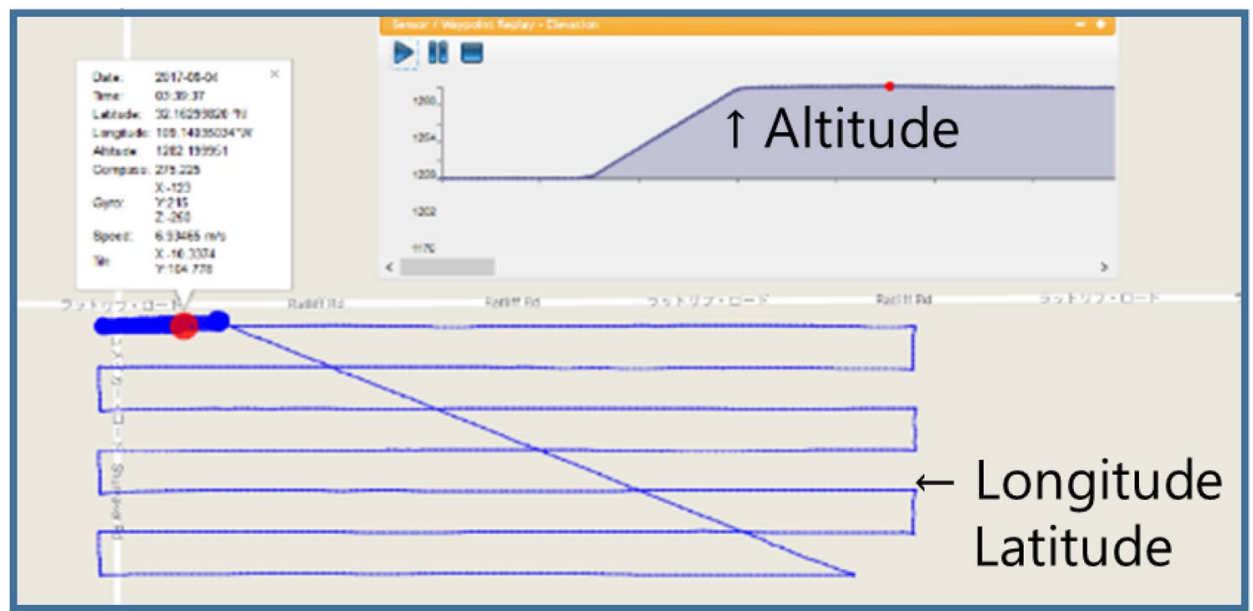


carried out for 23 trees in the orchard for this study, and 16 trees in another orchard that had mature trees. Using the linear regression equation of the model estimation against actual measurement value (Fig. 4), tree height maps were corrected.

\subsection{NDVI map creation}

The ortho-mosaic created above had an output as a GeoTIFF file of 8 bit integer value for each spectral band and the NDVI (Normalized Difference Vegetation Index) of each pixel was calculated. NDVI is a vegetation index that utilizes the plant properties that allow for absorption of visible red light and reflects near infrared light [4]. The calculation method is shown below.

$$
\mathrm{NDVI}=(\mathrm{NIR}-\mathrm{R}) /(\mathrm{NIR}+\mathrm{R})
$$

Here, NIR and R are the reflectance of the near-infrared light and visible red light, respectively. Mathematically this value is -1 to 1 , and it has a value close to 1 when the plant germinates. NDVI is one of the most used indices to evaluate vegetation and is used for many applications of cropland monitoring [3-13]

Since the cover crop which grows between the pecan trees also shows a high NDVI value similar to that of the pecan tree, a mask for separating the cover crop and the pecan tree was created using the DSM which eliminated the distortion in the section of the tree height map creation. We also made masks to evaluate pecan trees by variety.

\subsection{TIR map creation}

Activity monitoring was also carried out using TIR images. First, the output images were taken with a TIR camera and using the dedicated software the monochrome images had an integer value of 8 bit. The TIR images were taken with the camera and saved in a JPEG format with temperature information. The minimum and the maximum temperature of all images represented by DN (Digital Number) ranged from 0 to 255 . Then the GPS logger's position information was incorporated into the image and output was a GeoTIFF file.

The position of each image was manually corrected using GIS software and a mosaic image was created due the fact that the overlapping portions of the images did not perfectly coincide due to a deviation of position information.

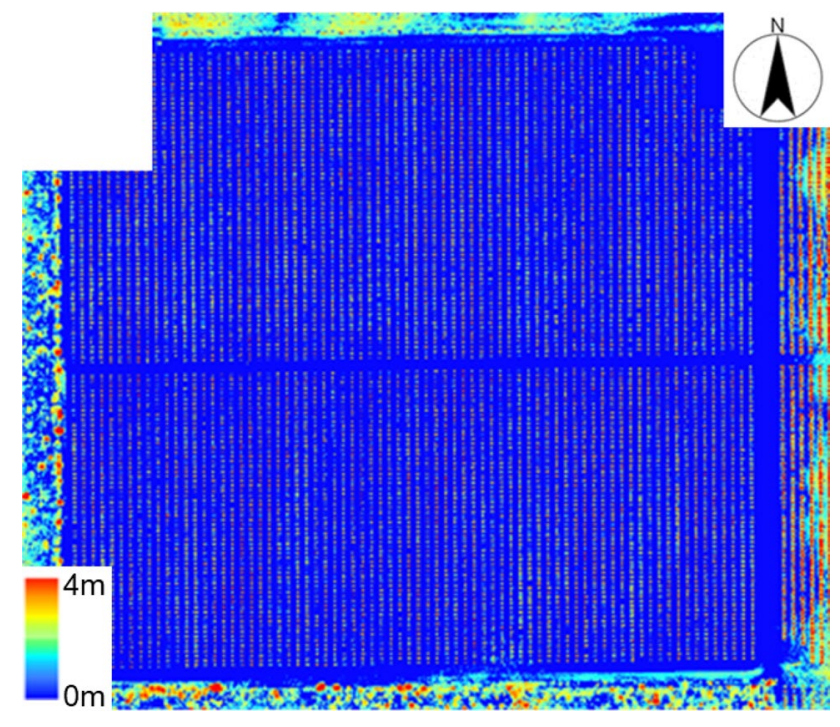

Fig. 5 Tree height map on August 5th, 2017

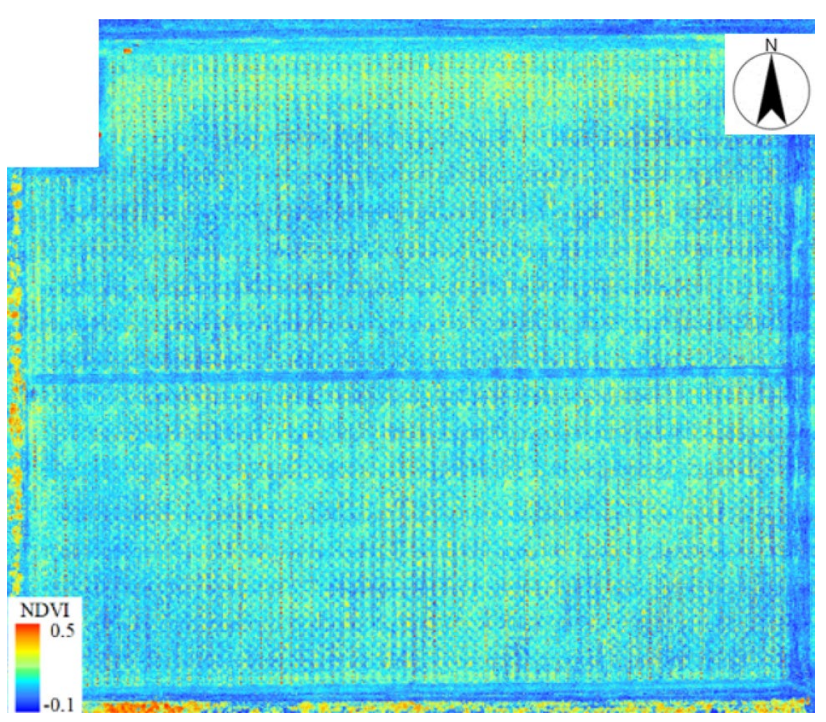

Fig. 6 NDVI map on June 3rd, 2017

\section{Results and discussion}

\subsection{Tree height map}

Figure 5 shows an estimated tree height map based on the August 5th 2017 images. We can see that areas with low and high values are scattered regardless of the row. By comparing this tree height map with that of another day, it is possible to estimate the amount of tree height growth during that period. By doing so, we can detect trees which grow remarkably or unsatisfactory in a vast orchard. 


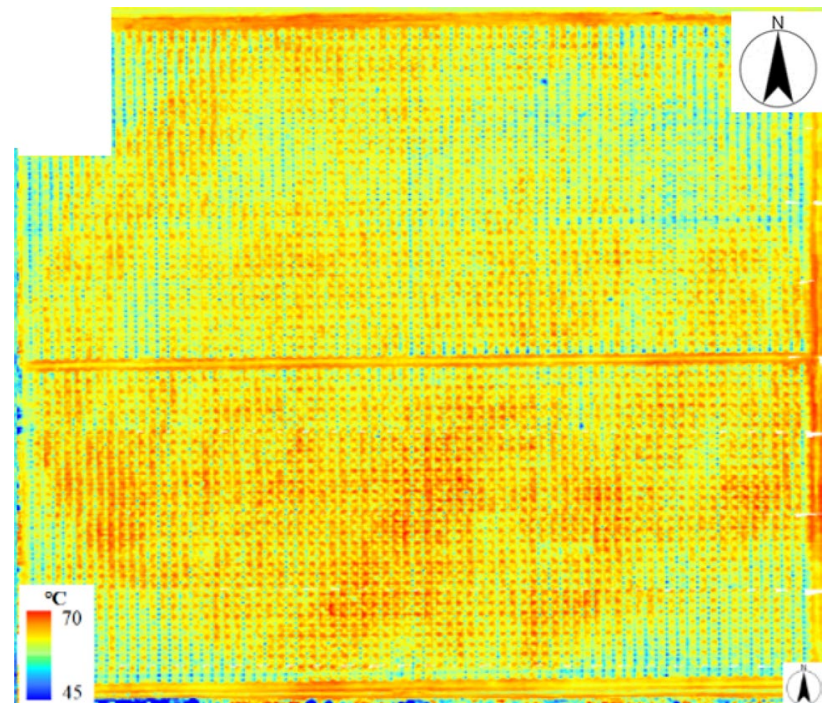

Fig. 7 Ground surface temperature map on June 3rd, 2017

\subsection{NDVI map}

Figure 6 shows NDVI map at northwest part of the orchard created from NIR images taken on June 3rd, 2017. In the NDVI map, the pecan trees and the cover crop growing between pecan trees shows high values. A line that crosses south part of the figure is a passageway for work vehicles, and this is bare soil where pecan trees and cover crops do not grow. Therefore, NDVI shows a low value around 0 at the line.

Since growing leaves on the trees varies depending upon the variety, shapes and values of the trees on NDVI map also varied depending on the specific varieties. Therefore, even within the same field, it is necessary to evaluate the value of NDVI separately for each variety.

In addition, when we analyzed the entire field, there were ranges where the high values of NDVI were dense and areas where low values were dense. It is not certain whether these differences are due to differences with the soil or the operation status of irrigation equipment.

\subsection{TIR map}

Figure 7 shows ground surface temperature map created from TIR images taken on June 3rd, 2017. This map indicated that the temperature was low at the areas where pecan trees were planted. This is expected as the plants have lower temperatures than soil, but this temperature information also served as a clue to the plant's activity. During the day, plants absorb sunlight and perform photosynthesis. At that time, the tree is actively transpiring which prevents the increase of the tree's own temperature. Therefore, temperature information can be also used to evaluate plant activity.

\subsection{Observation of a mysterious circle}

In addition, there was an interesting discovery on the surface temperature map using the TIR camera. There is a large circle that is visible within the orchard. According to past satellite images (Google earth, taken on May 20th, 2011) and information from the farm manager, alfalfa cultivation using pivot irrigation was conducted in this field before pecan tree cultivation. The map shows that the temperature is high inside the circle and low outside the circle. There is a possibility of the growth inhibition in areas showing high temperature.

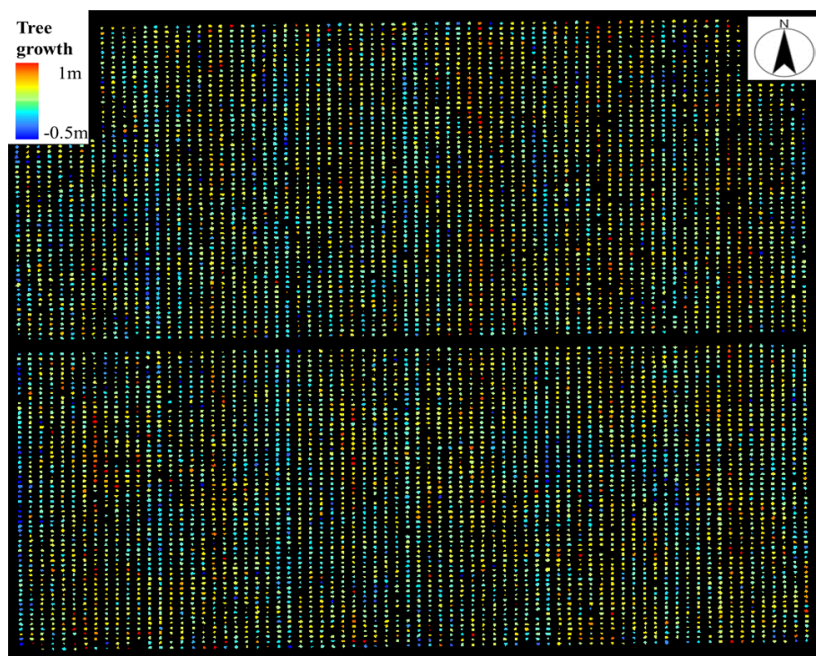

Fig. 8 Tree growth map from June 3rd to August 18th
Table 2 Mean value of NDVI and Temperature for each variety on June 3rd, 2017

\begin{tabular}{lcccccccc}
\hline & \multicolumn{2}{l}{ WACO } & & \multicolumn{2}{l}{ WESTERN } & & \multicolumn{2}{l}{ WICHITA } \\
\cline { 2 - 3 } & NDVI & Temp $\left({ }^{\circ} \mathrm{C}\right)$ & & NDVI & Temp $\left({ }^{\circ} \mathrm{C}\right)$ & & NDVI & Temp $\left({ }^{\circ} \mathrm{C}\right)$ \\
\hline ALL & 0.388 & 54.4 & & 0.403 & 52.6 & & 0.379 & 53.9 \\
IN_CIRCLE & 0.387 & 54.7 & & 0.405 & 53.0 & & 0.379 & 54.3 \\
OUT_CIRCLE & 0.393 & 52.5 & & 0.397 & 51.5 & & 0.382 & 51.9 \\
$P$ value* & 0.076 & $<0.001$ & & $<0.001$ & $<0.001$ & & 0.005 & $<0.001$ \\
\hline
\end{tabular}

*P value by Welch's test between in and out circle 
Table 3 Tree height growth (m) from June 3rd to August 18th

\begin{tabular}{llll}
\hline & WACO & WESTERN & WICHITA \\
\hline ALL & 0.530 & 0.221 & 0.358 \\
In_circle & 0.523 & 0.231 & 0.353 \\
Out_circle & 0.573 & 0.191 & 0.382 \\
$P$ value* & 0.010 & 0.104 & 0.009 \\
\hline
\end{tabular}

*P value by Welch's test between in and out circle

Table 2 shows average values of NDVI and Temperature for each variety at the target field on June 3rd, 2017. With the 'Waco' and 'Wichita' varieties the NDVI was higher in the value of the trees outside the circle than the value of the trees inside the circle. Temperature values of all varieties were lower outside the circle. As a whole trend, the trees planted outside the circle showed higher NDVI, and lower temperatures than the trees planted inside the circle. From this result, it can be interpreted that the trees on the outside of the circle are healthier than the trees on the inside of the circle.

Figure 8 shows a tree growth map constructed between June 3rd and August 18th. It is uneven and the trend is not clear as a whole. Therefore, for each variety, the average growth was obtained by comparing the trees inside and outside of the circle. For the analysis, trees exhibiting growth exceeding $1.5 \mathrm{~m}$ and trees where less growth was observed $(0.5 \mathrm{~m})$ were excluded. The reason for this was to avoid the replant pecan trees that had been introduced between June 3 and August 18, 2017. The reason for limiting the reduction amount to $0.5 \mathrm{~m}$ was to exclude trees that break by wind or self-weight.

Table 3 was obtained tree height at the inside and the outside of the circle for each variety, and obtaining the average growth amount of each. The average value of tree height growth showed that 'Waco' was the largest followed by 'Wichita' then 'Western'. Also, with all three varieties the height growth of the trees outside the circle were greater than the values of the trees inside the circle. This result was similar to the result obtained in Table 2, which may indicate that "the trees outside the circle are healthier than the trees inside the circle". It is possible that the soil where Alfalfa's pivot irrigation was performed may have a negative influence on the current growth of the trees.

Although the fact that leguminous plants, which include alfalfa, are known to make soil fertile [14], the trees do not seem to be responding to this and the area appears to be detrimental to the trees. As the soils in San Simon, Arizona, USA are known to be calcareous, we assume that this circle may actually be caused by salt accumulation which is often found in irrigation of arid land [15], but to conclude this, it is necessary to verify testing the soil. If this circle does represent increased salt deposition, this would explain why the trees within the circle are not growing as well and seem less healthy.

\section{Conclusions}

In this study, we established consecutive monitoring methods using UAV in pecan orchards of 64 ha each, in San Simon, Arizona, USA. The NDVI monitoring, tree height map creation and ground surface temperature analysis of trees by UAV with NIR/TIR camera were conducted for pecan nut orchards in San Simon, Arizona, USA. From the established continuous monitoring methods, one observed UAV image showed that 3 years after planting the pecan nuts, there were circular traces of alfalfa cultivation before pivot irrigation that no one noticed in the field.

Comparing the activity and height growth of the trees inside and outside the circle that appeared, it was found that the outside of the circle was better in both cases. Although the fact that leguminous plants, which include alfalfa, are known to make soil fertile [14], the trees do not seem to be responding to this and the area appears to be detrimental to the trees. As the soils in San Simon, Arizona, USA are known to be calcareous, we assume that this circle may actually be caused by salt accumulation which is often found in irrigation of arid land, but to conclude this, it is necessary to verify testing the soil.

In the future, we will investigate the relationship between several variables including the values of near infrared/thermal infrared data and the tree height map obtained in this research and the actual pecan nut yield, to verify the usefulness of the field monitoring method using UAV.

Acknowledgements This study was supported by North Bowie Farming, and The Foundation for the Promotion of Industrial Science (FPIS).

Open Access This article is licensed under a Creative Commons Attribution 4.0 International License, which permits use, sharing, adaptation, distribution and reproduction in any medium or format, as long as you give appropriate credit to the original author(s) and the source, provide a link to the Creative Commons licence, and indicate if changes were made. The images or other third party material in this article are included in the article's Creative Commons licence, unless indicated otherwise in a credit line to the material. If material is not included in the article's Creative Commons licence and your intended use is not permitted by statutory regulation or exceeds the permitted use, you will need to obtain permission directly from the copyright holder. To view a copy of this licence, visit http://creativecommons.org/licenses/by/4.0/.

\section{References}

1. Tilman, D., Cassman, K.G., Matson, P.A., Naylor, R., Polasky, S.: Agricultural sustainability and intensive production practices. Nature 418, 671-677 (2002)

2. Mulla, D.J.: Twenty-five years of remote sensing in precision agriculture: key advances and remaining knowledge gaps. Biosys. Eng. 114, 358-371 (2013) 
3. Zhang, C., Kovacs, J.M.: The application of small unmanned aerial systems for precision agriculture: a review. Precis. Agric. 13, 693-712 (2012)

4. Weier, J. and Herring, D.: Measuring Vegetation (NDVI \& EVI). Earth Observation. NASA, (2000). https://earthobservatory.nasa. gov/Features/MeasuringVegetation/. Accessed 29 March 2021

5. Benedetti, R., Rossini, P.: On the use of NDVI profiles as a tool for agricultural statistics: the case study of wheat yield estimate and forecast in Emilia Romagna. Remote Sens. Environ. 45, 311-326 (1993)

6. Hunt, E.R., Cavigelli, M., Daughtry, C.S.T., McMurtrey, J.E., Walthall, C.L.: Evaluation of digital photography from model aircraft for remote sensing of crop biomass and nitrogen status. Precis. Agric. 6, 359-378 (2005)

7. Swain, K.C., Jayasuriya, H.P.W., Salokhe, V.M.: Suitability of low-altitude remote sensing images for estimating nitrogen treatment variations in rice cropping for precision agriculture adoption. J. Appl. Remote Sens. 1, 013547 (2007)

8. Lelong, C.C.D., Burger, P., Jubelin, G., Roux, B., Labbe, S., Barett, F.: Assessment of unmanned aerial vehicles imagery for quantitative monitoring of wheat crop in small plots. Sensors 8 , 3557-3585 (2008)

9. Duan, T., Chapman, S.C., Guo, Y., Zheng, B.: Dynamic monitoring of NDVI in wheat agronomy and breeding trials using an unmanned aerial vehicle. Field Crop Res. 210, 71-80 (2017)

10. Muhammad, A.H., Yang, Mengjiao, Rasheed, Awais, Yang, Guijun, Reynolds, Matthew, Xia, Xianchun, Xiao, Yonggui, He, Zhonghu: A rapid monitoring of NDVI across the wheat growth cycle for grain yield prediction using a multi-spectral UAV platform. Plant Sci. 282, 95-103 (2019)

11. Modica, Giuseppe, Messina, Gaetano, De Luca, Giandomenico, Fiozzo, Vincenzo, Praticò, Salvatore: Monitoring the vegetation vigor in heterogeneous citrus and olive orchards. A multiscale object-based approach to extract trees' crowns from UAV multispectral imagery. Comput. Electron. Agri. 175, 105500 (2020)

12. Zhang, Chenglong, Valente, João., Kooistra, Lammert, Guo, Leifeng, Wang, Wensheng: Orchard management with small unmanned aerial vehicles: a survey of sensing and analysis approaches. Precis. Agri. (2021). https://doi.org/10.1007/ s11119-021-09813-y

13. Nomura, Ryota, Oki, Kazuo: Downscaling of MODIS NDVI by using a convolutional neural network-based model with higher resolution SAR data. Remote Sens. 13(4), 732 (2021)

14. Flynn, R., and Idown, J.: Nitrogen Fixation by Legumes. Publications. College of Agricultural, Consumer, and Environmental Sciences, New Mexico State University. https://aces.nmsu.edu/ pubs/_a/A129/ Accessed 10 July 2021

15. Sentis, I.P.: Soil salinization and land desertification. In: Rubio, J.L., Calvo, A. (eds.) Soil degradation and desertification in Mediterranean environments, pp. 105-129. Geoforma Ediciones, Logroño (1996)

Publisher's Note Springer Nature remains neutral with regard to jurisdictional claims in published maps and institutional affiliations. 